\title{
Integrating Digital Libraries with Instruction: Design and Promotion of Educational Applications
}

\author{
Kuo Hung Huang \\ National Chiayi University \\ Taiwan
}

\section{Introduction}

Digital libraries are collections of information represented as digital text, images, audio files, video files and other media, and are gaining increasing importance in people's everyday activities due to their continuously updated contents and services. Digital libraries store great amounts of a variety of information and deliver associated services to user communities using a variety of technologies (Frias-Martinez, Magoulas, Chen, \& Macredie, 2006). Although many websites provide a great deal of media including text, pictures, animation and maps, a rich assortment of media does not necessarily guarantee the valid delivery of information. In fact, most websites are structured for navigation according to the classification of materials, rather than the cognitive abilities of learners. Previous studies have reported that multimedia contents for navigation do nothing to help in the comprehension of knowledge (Eveland \& Dunwoody, 2000; Nilsson \& Mayer, 2002; Schwartz, Verdi, Morris, Lee, \& Larson, 2007). On the contrary, learners actively organize what they read to develop their own cognitive models to maintain the internal structure of the knowledge (Ausubel, 1978). Therefore, the content structured according to users' conceptual models will be appropriate for learners of diverse backgrounds. This chapter described the experiences of designing and promoting web-based learning environments with integrated digital libraries through a sequence of projects across a number of years.

\section{Digital archives project}

\subsection{Background}

The National Digital Archives Program (NDAP), sponsored by the National Science Council of Taiwan, was launched in 2002 (NDAP, 2003). The purpose of this program is to promote and coordinate content digitization and preservation at leading museums, archives, universities, research institutes and other content holders in Taiwan.

Since 2002, the program has being digitizing Taiwan's natural treasures and cultural heritage in order to be preserved and utilized in the digital era. However, another goal of the NDAP is to promote the utilization of the digital archives. Its missions are to popularize knowledge, improve information sharing, enhance education and life-long learning, as well as to improve literacy, creativity and quality. To achieve these goals, the training and 
promotion division under the NDAP has started projects to integrate NDAP resources with the curriculum in elementary and high schools.

The author, also a researcher of the above projects, designed a sequence of activities to promote the application of digital archives in the educational community. In doing so, the researcher first formed teams consisting of college and graduate students and in-service teachers, as well as scholars, and then provided basic training on the topic. When handling these projects, team members were asked to browse the available resources and interact with potential users in order to implement system and determine its usefulness. The information that emerged from the interaction with people in the educational community and from the process of solving various problems made the project more complete.

\subsection{Integrating GIS with digital libraries}

In the information age, activities in the real world are recorded in digital forms. People tend to use space, either physical or cyber, as a framework for understanding information (National Research Council, 2006). According to geography researchers, Geographic Information System (GIS) supports contextually rich student learning by extending the ability to perform inquiries, promoting in-depth data explorations, and by giving meaning to their works. Particularly for projects in the school community, GIS can facilitate the datato-information transition by providing the essential interpretive context that gives meaning to the data (National Research Council, 2006).

Social studies and geography are subjects that involve concepts of time and space, which must be integrated to understand the historical implications of land and culture, as well as changes in nature and humanity. Using space as a framework to understand domestic affairs helps students synthesize complex information regarding history and geography during instruction. According to Bunch and Lloyd (2006), the constructive use of maps in classrooms can promote the communication of information that is often too complex to easily express with words. With the ability to efficiently provide large amounts of visual information, mapping tools such as GIS offer new ways to present spatial information and deliver an engaging learning experience. As a tool for the presentation of location-based subject matter, GIS has helped social scientists to search for patterns and order in society and discover knowledge in cyberspace (Slocum, 1999; Sui, 2004).

Based on the aforementioned rationale, this study designed websites with GIS interfaces covering geography and digital libraries to help students interact and learn through the use of digital archives. After evaluating the available resources of digital archives and the feasibility of the projects, this study decided to use web-based GIS technologies and Flash animations to produce works useful for young students. The project was implemented in three stages: the implementation stage, the promotion stage and the enhancement stage.

\section{Implementation stage: Integrating with electronic maps}

\subsection{Contents}

Chiayi, a historical city in Taiwan, has played an important role in the past hundred years of Taiwan history. Thematic information about Chiayi includes language, history, geography, nature and arts. Data related to Chiayi City is identified in some of the archives, which consists of different types of data including images, texts, maps, drawings and sound collections. To reduce the waiting time for visualization, a client-server architecture was implemented. The front-end interface used Flash technology and the web server stored the archive data. 


\subsection{Design}

GIS provides the users with intuitive perception through information visualization. Atlases and photos describe the landscape created by either natural processes or human activities during a period of time, annotate what happened during specific space-time conditions, and reflect the culture of a place (Summerby-Murray, 2001). Reviewing maps of the same place from different periods can assist users to rehabilitate history and understand changes in the environment, society and culture. In order to correlate unstructured information such as images, sounds, drawings and textual descriptions with spatial information, the system designed three levels of interaction to represent the complex associations: an interactive map, a time map and a hyperlinked map. There were two main user interface designs to facilitate learning.

The first component was an interactive map. Layers of maps, which are similar to GIS, were used as the information visualization technology to organize and display various kinds of information for every point on a computerized map. This involved powerful, complex computer databases that organized information around a specific location (see Fig. 1). Users could select a thematic representation or an automatic combination of layers of maps. The thematic representation was selected and tested as a better view to comprehend the information about a specific topic about Chiayi (see Fig. 2).

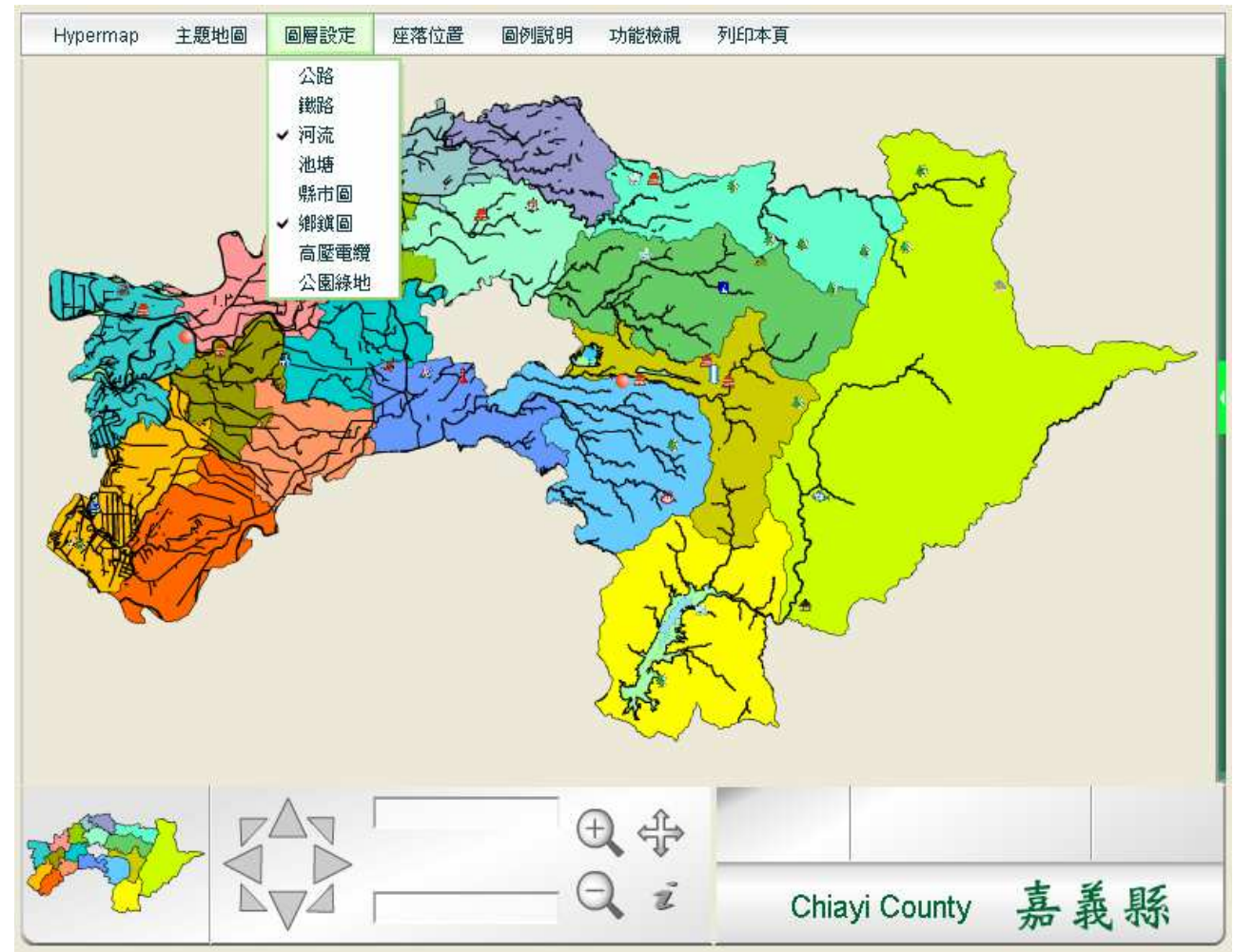

Fig. 1. Users can zoom, move and select different map layers 


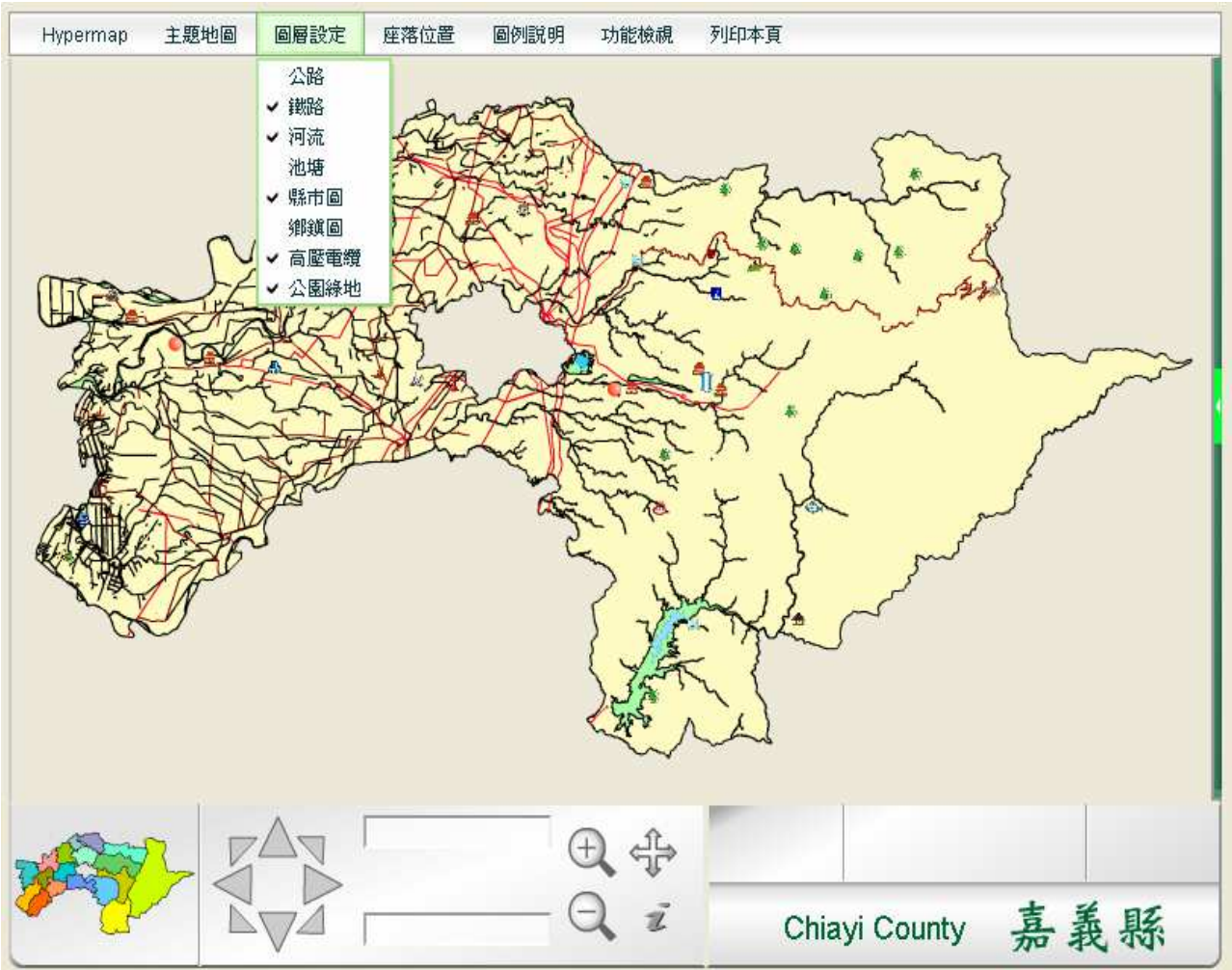

Fig. 2. Users can select map layers to obtain a better view about a specific topic

The other design was a time map. Three major challenges for a time-series data exploration system are providing algorithms for the analysis and creation of metadata, filtering out data that is uninteresting, and the interactive exploration of the regions of interest. In this project, a time map was used a tool to filter out uninteresting data (Grady, Flanery, Donato, \& Schryver, 2002). Sliders, which are a generic user input mechanism for specifying a numeric value from a range, were used to control a threshold filtering the entities shown on the display. In this level of interaction, the time map provided users with a tool to move between different representations, thereby enabling them to explore the data from several perspectives. The data visualization slider, designed as a chronicle scale, was tied to a set of map layers. A user operated the slider by holding down the left mouse button and moving to a new position. Information within the time interval would be displayed on the map (Figure 3). In addition, a hyperlinked map was designed to retrieve further information. A straightforward approach of enabling users to dynamically retrieve time-sensitive information is to link further information to the entities distributed over the map, based on the values in the chronicle field (Risch, et al., 1997). Users were able to click on each entity shown on the map and retrieve additional information through a pop-up window that appeared. By clicking on keywords on the windows, the hyperlinks would display more information stored in the original archives (Figure 4). 


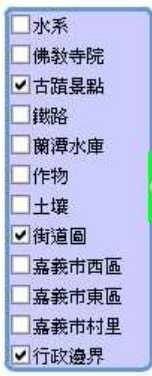

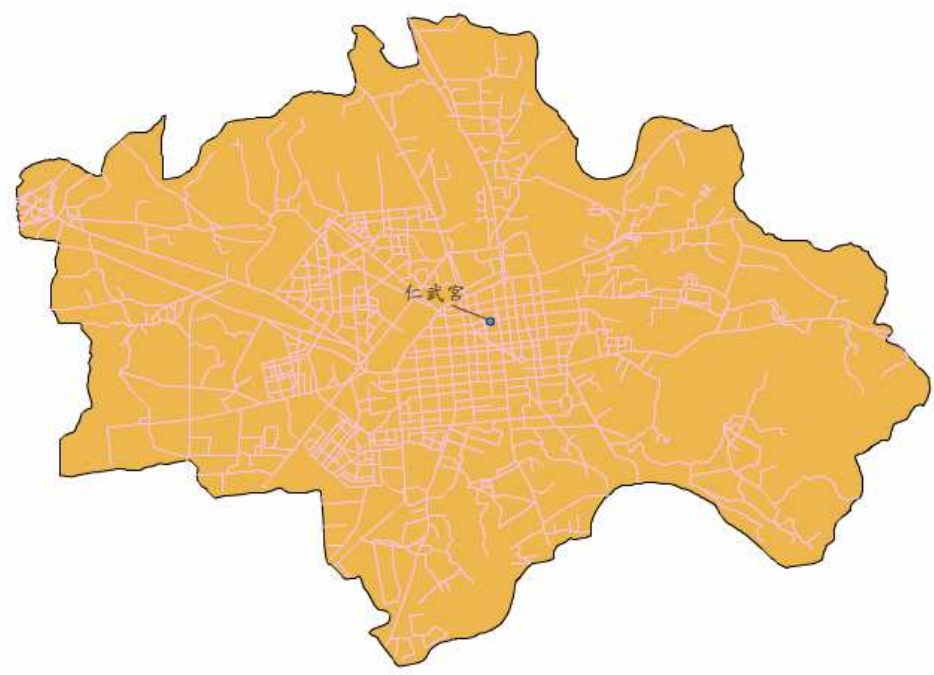

西元 1600

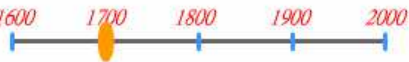

嘉義市

Fig. 3. The slider sets the calendar year and related information is shown.

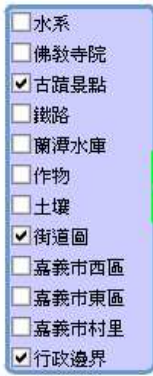

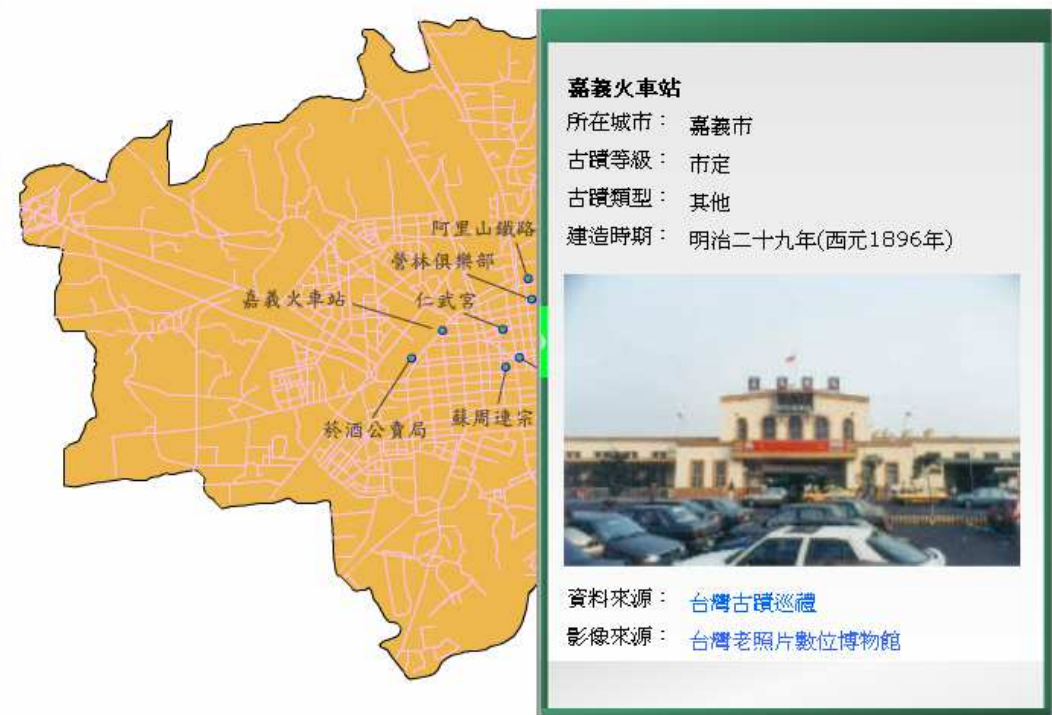

西元 $1600 \quad 1700 \quad 1800 \quad 1900 \quad 2000$ 嘉義市

Fig. 4. A pop-up window and hyperlinks retrieve information. 


\subsection{Instruction and evaluation}

To evaluate the effects of these learning environments, two empirical studies were conducted in two elementary schools respectively (see Figure 5). In the first study, the subjects were 32 fourth-grade students. The teacher integrated the electronic map and digital archives with classroom instruction. The achievement test after instruction showed that the students performed significantly better than those under traditional instruction. In the second study, project-based learning activities were arranged to collect qualitative data for assessment. After becoming familiar with the resources, the students were divided into several groups to complete their own project. The project for each group was to construct a thematic map based on the electronic map and digital resources. Students in each group participated in the activities of discussing the theme, distributing tasks, collecting data, constructing the map and preparing a slide to present their works. Analysis showed that the students possessed a positive attitude toward using digital libraries for constructing their own presentation. In addition, the teacher was convinced of the educational advantages of using digital archives. Through watching the students working together as a team, she realized that the digital archives were playing the role of mediating the students' active learning. In addition to factual knowledge, the students also learned by doing.
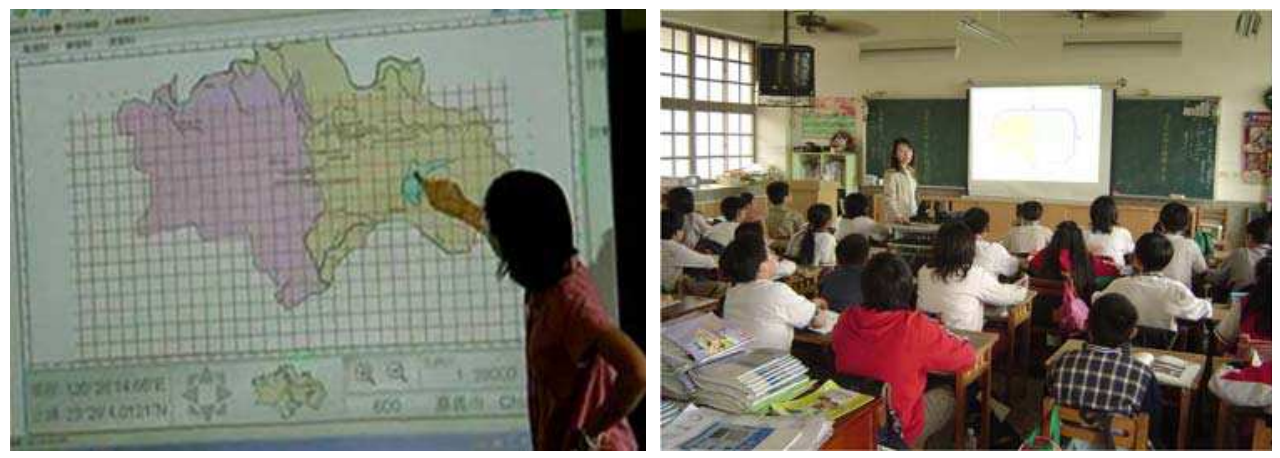

Fig. 5. Two teachers using digital libraries in classroom instruction

\section{Promotion stage: Additional media and workshops}

\subsection{Extension and promotion}

The successful experience encouraged the research team to promote additional learning resources. Resources on Chiayi City and Chiayi County were developed in the previous stage. However, there are 16 cities or counties in Taiwan. The research team utilized the same design pattern to create resources on the other 14 cities or counties (see Figure 6). Later, several training workshops were held to train teachers how to use the digital libraries. These teachers were first introduced to the concept of digital libraries and their educational applications. Then, the speaker demonstrated how to use a web-based interactive map to retrieve resources related to the curriculum. At the end of the workshops, questionnaires were dispatched to assess their impressions and intention to use these materials. Table 1 shows the workshop attendants' positive attitude toward these materials. 


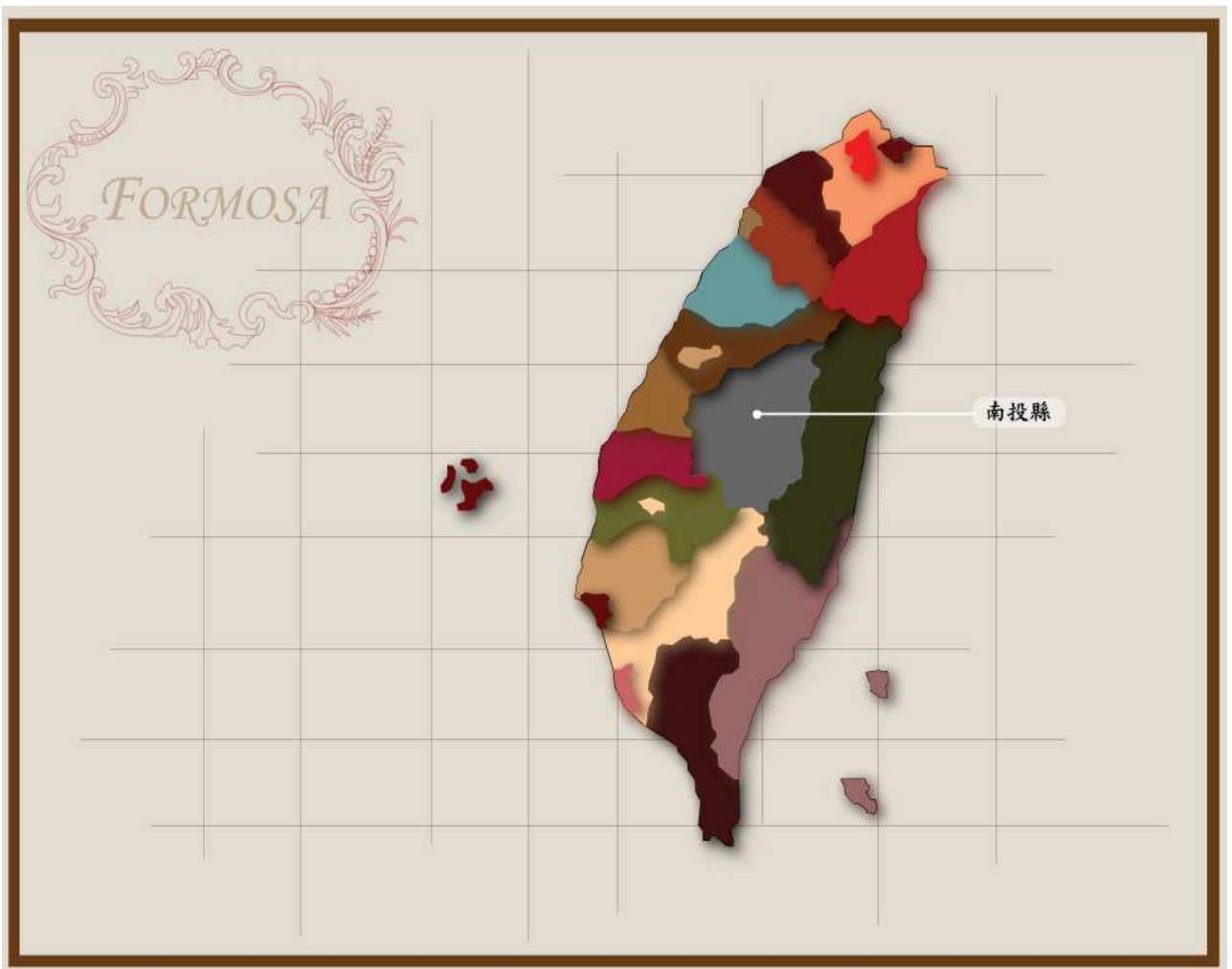

Fig. 6. Users can choose specific cities in Taiwan when accessing the digital library.

\begin{tabular}{|l|c|c|c|c|c|}
\hline \multicolumn{1}{|c|}{ Items } & $\begin{array}{c}\text { Strongly } \\
\text { agree }\end{array}$ & agree & $\begin{array}{c}\text { neutra } \\
1\end{array}$ & $\begin{array}{c}\text { disagre } \\
\text { e }\end{array}$ & $\begin{array}{c}\text { Strongly } \\
\text { disagree }\end{array}$ \\
\hline This web-site is well designed & 12 & 26 & 3 & 0 & 0 \\
\hline $\begin{array}{l}\text { This website will help to comprehend the } \\
\text { contents }\end{array}$ & 22 & 15 & 4 & 0 & 0 \\
\hline You will use this website in your instruction & 13 & 23 & 4 & 1 & 0 \\
\hline
\end{tabular}

Table 1. Workshop attendants' attitude toward the developed materials $(\mathrm{N}=41)$

\subsection{Follow-up evaluation}

Six months after the workshops, the research team interviewed the attendants on the phone to understand the status of their digital library utilization. Surprisingly, none of the interviewees actually used these resources in the classroom. The major reason for not using these media was a lack of time. Since the textbooks used in the classroom were not cityoriented, teachers had to spend time retrieving related information for certain cities. Teachers were too busy to re-organize these materials for instruction. If the resources could be designed as independent components according to the concepts in the textbooks, teachers could easily select related media and assemble them as teaching resources. 


\section{Enhancement stage: Revision for teachers' needs}

In light of the importance of providing easy access to media for instruction, the research team selected themes on domestic geography in the social studies curriculum as the teaching content and designed computer animations as the instructional media to foster teachers' interests in integrating technology with classroom instruction. There were two major enhancements: one was to organize the resources into the structure of the textbooks, and the other was to organize the resources into themes.

\subsection{Resources in textbook structure}

The goal at this stage was to bridge the gap of expected usability between the instruction material developers and the practicing teachers. From the perspective of the teachers, integrating the GIS and digital archives with the existing curriculum as packages would help teachers to use these instruction materials. The tasks of this project included selecting related units in the textbooks, searching for useful resources in the digital archives, and then designing instruction plans and digital resources. Table 2 shows the selected units and the associated media.

\begin{tabular}{|c|c|c|c|}
\hline $\begin{array}{c}\text { School } \\
\text { year }\end{array}$ & Unit Name & $\begin{array}{l}\text { Number of } \\
\text { Lessons }\end{array}$ & Media \\
\hline \multirow{6}{*}{$\begin{array}{l}\text { Grade } \\
\text { Four }\end{array}$} & Name and location of hometown & 3 & Interactive maps \\
\hline & $\begin{array}{l}\text { Natural environment and living of } \\
\text { hometown }\end{array}$ & 2 & animations \\
\hline & Development of hometown & 2 & animations \\
\hline & $\begin{array}{l}\text { Festivals and folk cultural activities in } \\
\text { hometown }\end{array}$ & 2 & Video clips \\
\hline & Unique sights and products in hometown & 2 & pictures \\
\hline & Tours around hometown & 2 & maps \\
\hline \multirow{6}{*}{$\begin{array}{l}\text { Grade } \\
\text { Five }\end{array}$} & Where is Taiwan & 2 & maps \\
\hline & Natural environment of Taiwan & 3 & Satellite images \\
\hline & Resources in Taiwan & 2 & pictures \\
\hline & Population and change of towns & 2 & Interactive maps \\
\hline & Area and traffic & 3 & Interactive maps \\
\hline & Care for Taiwan & 2 & pictures \\
\hline \multirow{2}{*}{$\begin{array}{l}\text { Grade } \\
\text { Seven }\end{array}$} & Environment of Taiwan & 6 & pictures \\
\hline & History of Taiwan & 6 & animations \\
\hline
\end{tabular}

Table 2. Textbook units selected for media development

\subsection{Resources in theme structure}

The themes related to geographic subject content in the elementary and junior high school social studies curriculum were associated with the topics of population, economy, settlement and traffic, as well as regional development and environmental protection. With the combination of texts, pictures, digital maps, simulated animations and games, these elearning resources supported teachers in constructing a learning environment to engage students in learning and discussion. Animated simulations were used to illustrate abstract 
concepts. For example, an animation with different phases of urbanization aroused students' feelings towards various environments, and provided students with a context to share their experiences (see Fig. 7). This was helpful for teachers to explain the process of how a settlement develops in the suburbs. As Brookfield (1987) pointed out, the process of internally examining and exploring an issue of concern, when triggered by a relevant experience, creates and clarifies meaning in terms of self and results in a changed conceptual perspective.
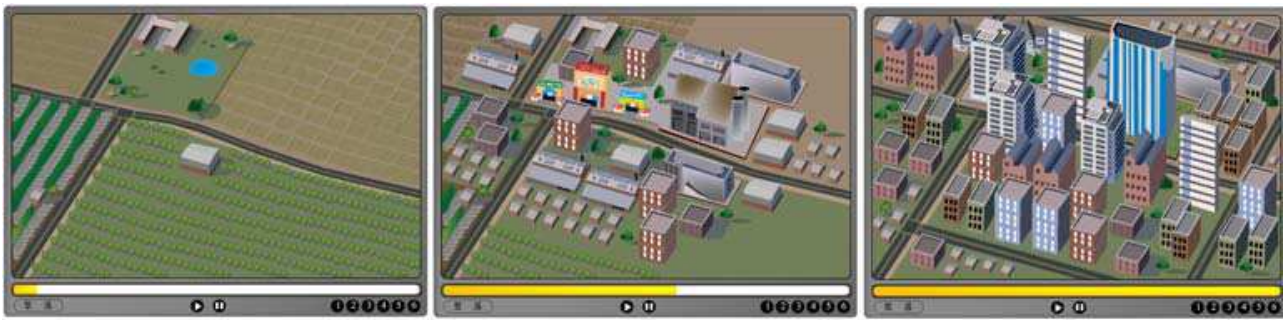

Fig. 7. Simulation of the urbanization process. From left to right: Phase 1, 3 and 6.

Thematic maps were used for cross-referencing to create meaningful learning. Animations provided cross references associated with a particular topic, to encourage students to reason and seek evidence for arguments. To develop their critical perspective, students need to reason within various points of view and use evidence in order to draw conclusions, make decisions or seek solutions. For example, to answer why the intensive construction of traffic infrastructure was needed on the west coast, a link to a population distribution map and a traffic network map provided evidence for reasoning (see Fig. 8). In addition, statistical data could be converted into a graphical form to facilitate comprehension (see Fig. 9).
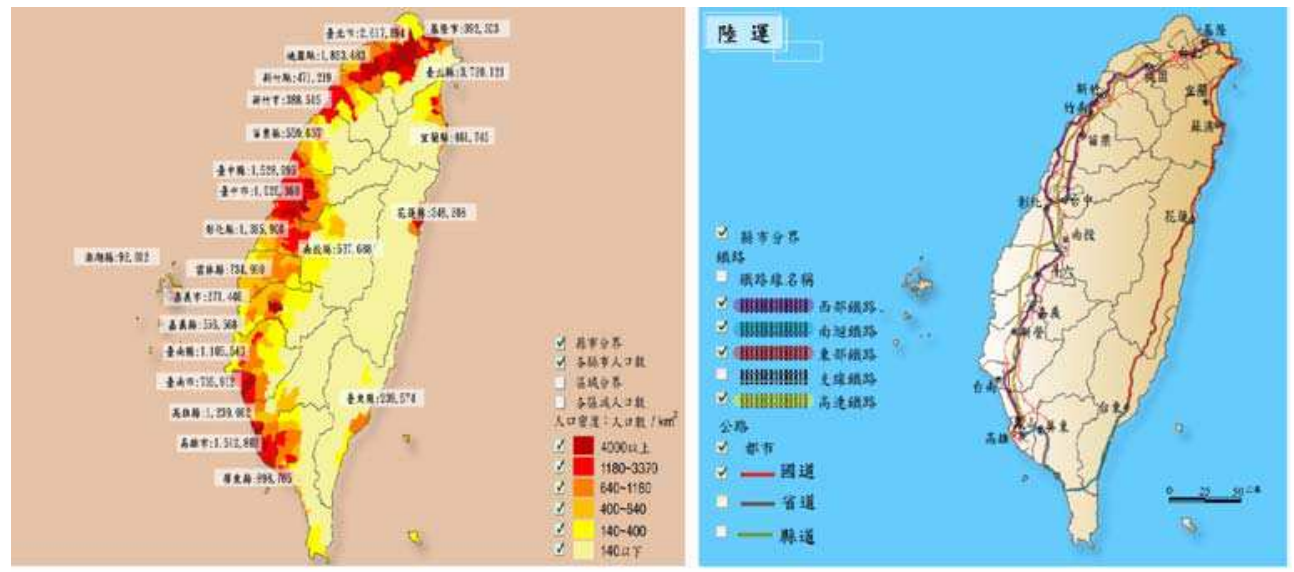

Fig. 8. Maps referencing traffic issues. The left is the population distribution and the right is the traffic network. 

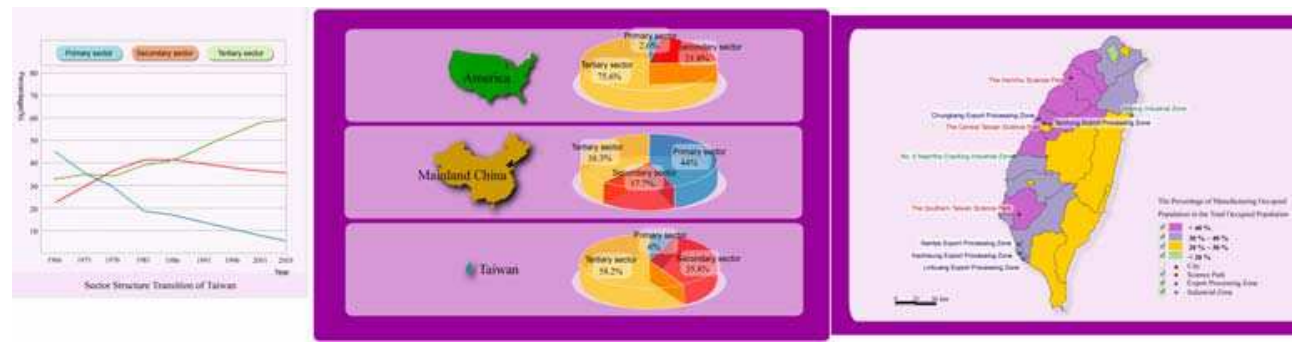

Fig. 9. Visualization of economic transition and distribution of industrial parks

\section{Future works}

The future work is to develop digital media and activities on interactive whiteboards based on the digital archive resources. The research team will first search and organize the resources in the digital archive project, and then integrate in a spatial concept with touchcontrol operations to design efficient instructional activities and media. For example, as shown in Fig. 10, an interactive tool for settlement planning was developed for students to practice their urban design. Using drag and drop operations, students arranged constructions such as buildings or airports according to their ideal locations to build a village or city. Students' works were then be presented and evaluated by classmates. Students with diversified backgrounds and values designed cities with a variety of features and functionalities. The teacher used challenging questions to inspire students to respond, expand and develop the topics during critical-talk lessons. In addition, an interactive quiz to compare traffic infrastructure was used to attract students' attention and efforts on reaching consensus (see Fig. 11). According to Moon (2008), peer assessment provides practice in making judgments on the basis of evidence. The act of assessing the work of another is a matter of making a judgment. It more deeply involves learners in the process of metacognitive critical thinking skills.
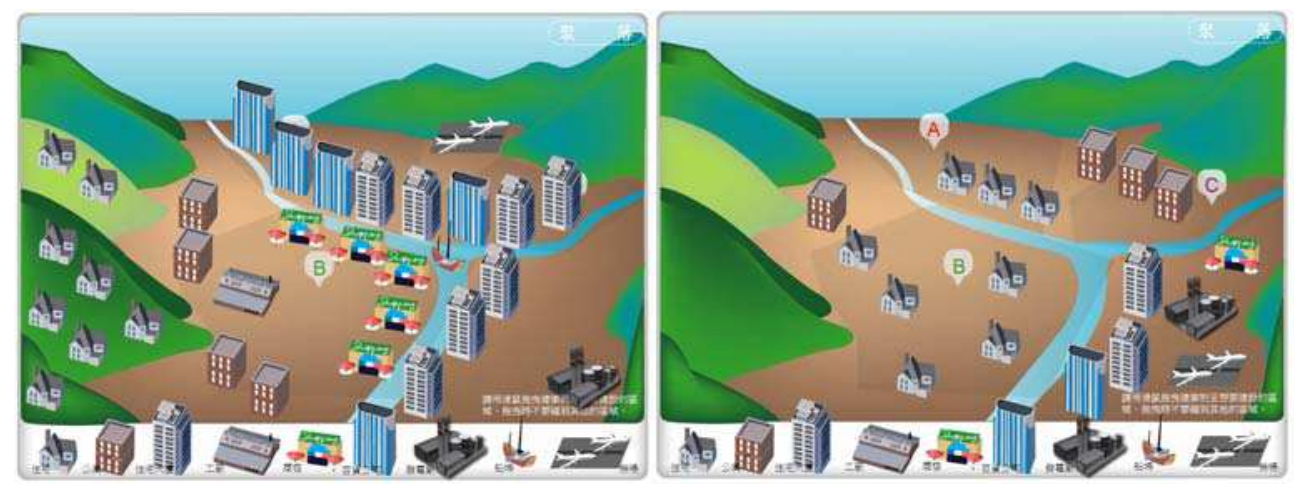

Fig. 10. Settlement designs by two students. 


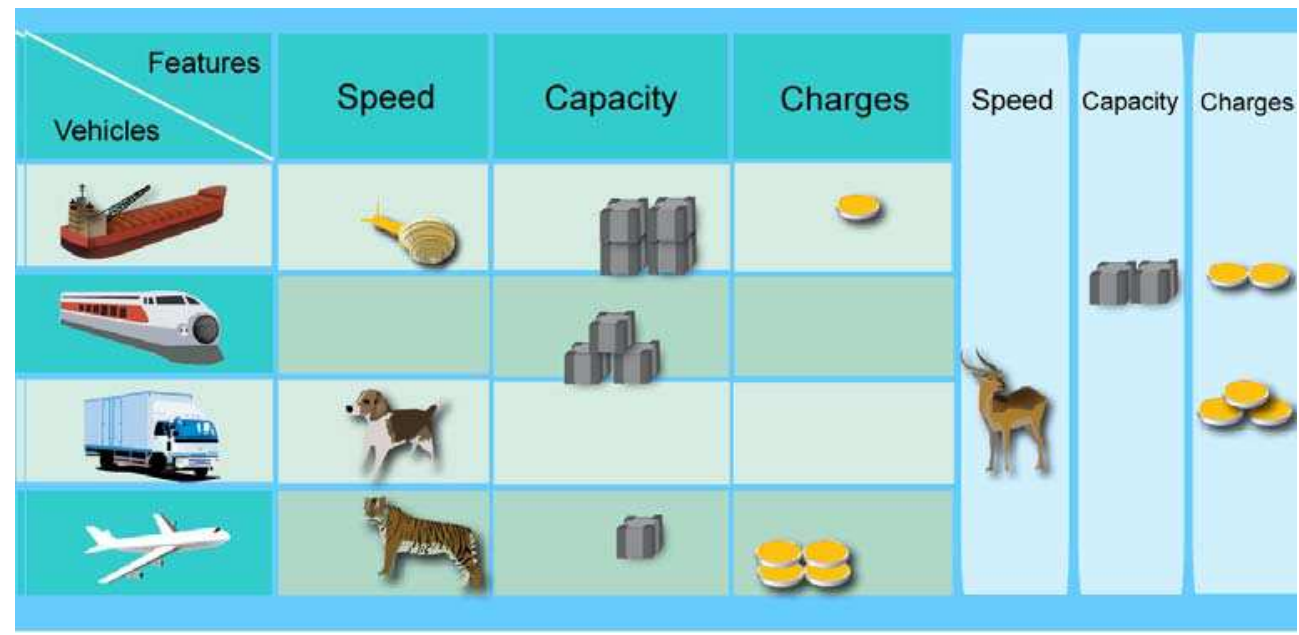

Fig. 11. Interactive matching quiz partly completed by a student

\section{Conclusions}

Web-based instruction is known for its media-rich online environment, providing users access to remote resources for self-paced learning. Although a number of schools have designed educational websites to integrate in-classroom learning activities with the school curriculum, designing effective learning resources based on sound educational theory will encourage students and teachers to use them more often.

Constructivist educational models are based on the theory that instead of being passive receivers of information, learners should be active explorers of their own understandings. Teachers and technology merely serve as mediators or guides to support the development of learners. Several researchers have treated technology as a vehicle to foster active learning and believe that such learning environments motivate and facilitate the acquisition of knowledge by providing an intuitively comprehensible context (Milson \& Earle, 2007; Papert, 1980; Piburn, Reynolds, MacAuliffe, Leedy, \& Birk, 2005).

The prevalence of computer usage in schools is driving the need to understand its effects on learning when technology is integrated within instruction. The experiences of this project addressed the needs of teachers to enhance students' geographical knowledge through the use of GIS-based resources. Such knowledge is a useful reference when examining issues related to educational practices using digital libraries.

\section{References}

Ausubel, D. P. (1978). Educational Psychology: A Cognitive View. New York: Holt McDougal.

Brookfield, S. (1987). Developing critical thinkers: Challenging adults to explore alternative ways of thinking and acting. San Francisco: Jossey-Bass.

Bunch, R. L., \& Lloyd, R. E. (2006). The cognitive load of geographic information. The Professional Geographer, 58(2), 209-220. 
Eveland, W., \& Dunwoody, S. (2000). Examining information processing on the WWW using think aloud protocols. Media Psychology, 2(3), 219-244.

Frias-Martinez, E., Magoulas, G., Chen, S., \& Macredie, R. (2006). Automated user modeling for personalized digital libraries. International Journal of Information Management, 26, 234-248.

Grady, N., Flanery, R., Donato, J., \& Schryver, J. (2002). Issues in time-series and categorical data exploration. In U. Fayyad, G. G. Grinstein \& A. Wierse (Eds.), Information Visualization in Data Mining and Knowledge Discovery (pp. 229-235). San Francisco: Morgan Kaufmann.

Milson, A. J., \& Earle, B. D. (2007). Internet-based GIS in an inductive learning environment: A case study of ninth-grade geography students. Journal of Geography, 106(6), 227237.

Moon, J. (2008). Critical thinking. New York: Routledge.

National Research Council (2006). Learning to think spatially: GIS as a support system in the K12 curriculum. Washington D.C.: National Academies Press.

NDAP (2003). NDAP Introduction, Accessed at http://www.ndap.org.tw/1_org_en/introduction.php

Nilsson, R. M., \& Mayer, R. E. (2002). The effects of graphics organizers giving cues to the structure of a hypertext document on users' navigation strategies and performance. International Journal of Human-Computer Studies, 57, 1-26.

Papert, S. (1980). Mindstorms. London: Harvester Wheatsheaf.

Piburn, M. D., Reynolds, S. J., MacAuliffe, C., Leedy, D. E., \& Birk, J., P. (2005). The role of visualization in learning from computer-based images. International Journal of Science Education, 27(5), 513-527.

Risch, S., Rex, D. B., Dowson, S. T., Walters, T. B., May, R. A., \& Moon, B. D. (1997). The STARLIGHT information visualization on system. Proceedings of the IEEE Conference on Information Visualization, 42-49.

Schwartz, N. H., Verdi, M. P., Morris, T. D., Lee, T. R., \& Larson, N. K. (2007). Navigating web-based environments: Differentiating internal spatial representations from external spatial displays. Contemporary Educational Psychology, 32(4), 551-568.

Slocum, T. (1999). Thematic Cartography and Visualization. Upper Saddle River, NJ: Prentice Hall.

Sui, D. Z. (2004). GIS, Cartography, and the ? 黨hird Culture?? Geographic Imaginations in the Computer Age. Professional Geographer, 56(1), 62-72.

Summerby-Murray, R. (2001). Analysing heritage landscapes with historical GIS: Contributions from problem-based inquiry and constructivist pedagogy. Journal of Geography in Higher Education, 25(1), 37-52. 


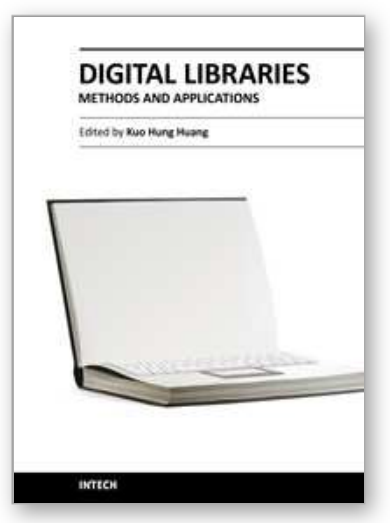

\author{
Digital Libraries - Methods and Applications \\ Edited by Dr. Kuo Hung Huang
}

ISBN 978-953-307-203-6

Hard cover, 220 pages

Publisher InTech

Published online 04, April, 2011

Published in print edition April, 2011

Digital library is commonly seen as a type of information retrieval system which stores and accesses digital content remotely via computer networks. However, the vision of digital libraries is not limited to technology or management, but user experience. This book is an attempt to share the practical experiences of solutions to the operation of digital libraries. To indicate interdisciplinary routes towards successful applications, the chapters in this book explore the implication of digital libraries from the perspectives of design, operation, and promotion. Without common agreement on a broadly accepted model of digital libraries, authors from diverse fields seek to develop theories and empirical investigations that to advance our understanding of digital libraries.

\title{
How to reference
}

In order to correctly reference this scholarly work, feel free to copy and paste the following:

Kuo Hung Huang (2011). Integrating Digital Libraries with Instruction: Design and Promotion of Educational Applications, Digital Libraries - Methods and Applications, Dr. Kuo Hung Huang (Ed.), ISBN: 978-953-307-2036, InTech, Available from: http://www.intechopen.com/books/digital-libraries-methods-andapplications/integrating-digital-libraries-with-instruction-design-and-promotion-of-educational-applications

\section{INTECH}

open science | open minds

\section{InTech Europe}

University Campus STeP Ri

Slavka Krautzeka 83/A

51000 Rijeka, Croatia

Phone: +385 (51) 770447

Fax: +385 (51) 686166

www.intechopen.com

\section{InTech China}

Unit 405, Office Block, Hotel Equatorial Shanghai

No.65, Yan An Road (West), Shanghai, 200040, China

中国上海市延安西路65号上海国际贵都大饭店办公楼405单元

Phone: +86-21-62489820

Fax: +86-21-62489821 
(C) 2011 The Author(s). Licensee IntechOpen. This chapter is distributed under the terms of the Creative Commons Attribution-NonCommercialShareAlike-3.0 License, which permits use, distribution and reproduction for non-commercial purposes, provided the original is properly cited and derivative works building on this content are distributed under the same license. 